\title{
Plant sex determination and sex chromosomes
}

\author{
D Charlesworth \\ Institute of Cell, Animal and Population Biology, University of Edinburgh, Scotland, UK
}

\begin{abstract}
Sex determination systems in plants have evolved many times from hermaphroditic ancestors (including monoecious plants with separate male and female flowers on the same individual), and sex chromosome systems have arisen several times in flowering plant evolution. Consistent with theoretical models for the evolutionary transition from hermaphroditism to monoecy, multiple sex determining genes are
\end{abstract}

involved, including male-sterility and female-sterility factors. The requirement that recombination should be rare between these different loci is probably the chief reason for the genetic degeneration of $Y$ chromosomes. Theories for $Y$ chromosome degeneration are reviewed in the light of recent results from genes on plant sex chromosomes.

Heredity (2002) 88, 94-101. DOI: 10.1038/sj/hdy/6800016

Keywords: dioecy; sex linkage; Y chromosomes; Silene latifolia

\section{Introduction: why are plant sex chromosomes of particular interest?}

The genetic control of sex determination is becoming well understood in several animal systems, particularly Drosophila melanogaster, Caenorhabditis elegans and mammals. In plants, understanding the sex determination system is closely connected with understanding how separate sexes evolved, and current theoretical ideas about this also illuminate the evolution of sex chromosomes. Angiosperms are also of particular interest for empirical studies of sex chromosome evolution, because they probably evolved separate sexes repeatedly and relatively recently. Other plants, particularly Bryophytes (see Okada et al, 2001), also have interesting independently evolved sex chromosomes.

In many sexually reproducing plant species (and some animals) all individuals are essentially alike in their gender condition. Many such 'sexually monomorphic' species are hermaphroditic. The term 'cosexual' (Lloyd, 1984) is used when individual plants have both sex functions, whether present within each flower (hermaphrodite), or in separate male and female flowers (monoecious). A minority of plant species are 'sexually polymorphic', including dioecious species, with separate males and females (Table 1). Many dioecious species with hermaphrodite relatives have evident rudiments of opposite sex structures in flowers of plants of each sex, suggesting recent evolution of unisexual flowers (Darwin, 1877). The low frequency and scattered taxonomic distribution of dioecy and sex chromosomes suggest that cosexuality is the ancestral angiosperm state (Figure 1) (Charlesworth, 1985; Renner and Ricklefs, 1995. Sex chromosomes therefore probably evolved repeatedly and quite recently.

Correspondence: D Charlesworth, Institute of Cell, Animal and Population Biology, University of Edinburgh, Ashworth Laboratory King's Buildings, West Mains Road., Edinburgh EH9 3JT, UK

E-mail: Deborah.Charlesworth@ed.ac.uk
In some plant taxa, it is possible to estimate how many times dioecy has evolved, and how long ago. Dioecy probably evolved twice in the Hawaiian genus Schiedia (Weller et al, 1995). The best studied case at present is the large genus Silene, in the same family (Caryophyllaceae). Many Silene species are gynodioecious and others are hermaphroditic. A phylogeny constructed from internal transcribed spacer (ITS) sequences of nuclear ribosomal RNA genes of Silene species suggests two origins of dioecy in this genus also (Desfeux et al, 1996). Using a molecular clock, these data suggest an age of probably less than 20 million years for the heteromorphic sex chromosomes of the close relatives Silene latifolia and S. dioica. Comparative analysis suggests that dioecious lineages often have short evolutionary lives (Heilbuth, 2000). Thus separate sexes may have evolved more than 100 times in the flowering plants, given that 160 families have dioecious members.

\section{The genetics of sex determination in plants, and plant sex chromosomes}

Sex inheritance and sex chromosomes in plants are strikingly similar to those in animals. The majority of plants studied have heterozygous males, or, when the chromosomes are visibly different (perhaps half of plants that have separate sexes, see Westergaard, 1958), male heterogamety ( $X Y$ males, $X X$ females). In many dioecious plants, males are 'inconstant', ie produce occasional fruits (Lloyd, 1975b; Lloyd and Bawa, 1984). Self fertilisation of such plants in several species has provided genetic evidence that males are heterozygous. As will be explained below, the male genotype must include a dominant suppressor of femaleness $\left(S u^{\mathrm{F}}\right)$. On selfing, a 3:1 ratio of males to females is expected if $S u^{\mathrm{F}} / S u^{\mathrm{F}}$ is viable, or 2:1 if the $\mathrm{Y}$ chromosome is genetically degenerated and this genotype is inviable. Each of these ratios has been found (Westergaard, 1958; Testolin et al, 1995). Some plant $Y$ chromosomes are therefore at least partially genetically degenerate. 
Table 1 Sex and gender systems of sexually reproducing flowering plants

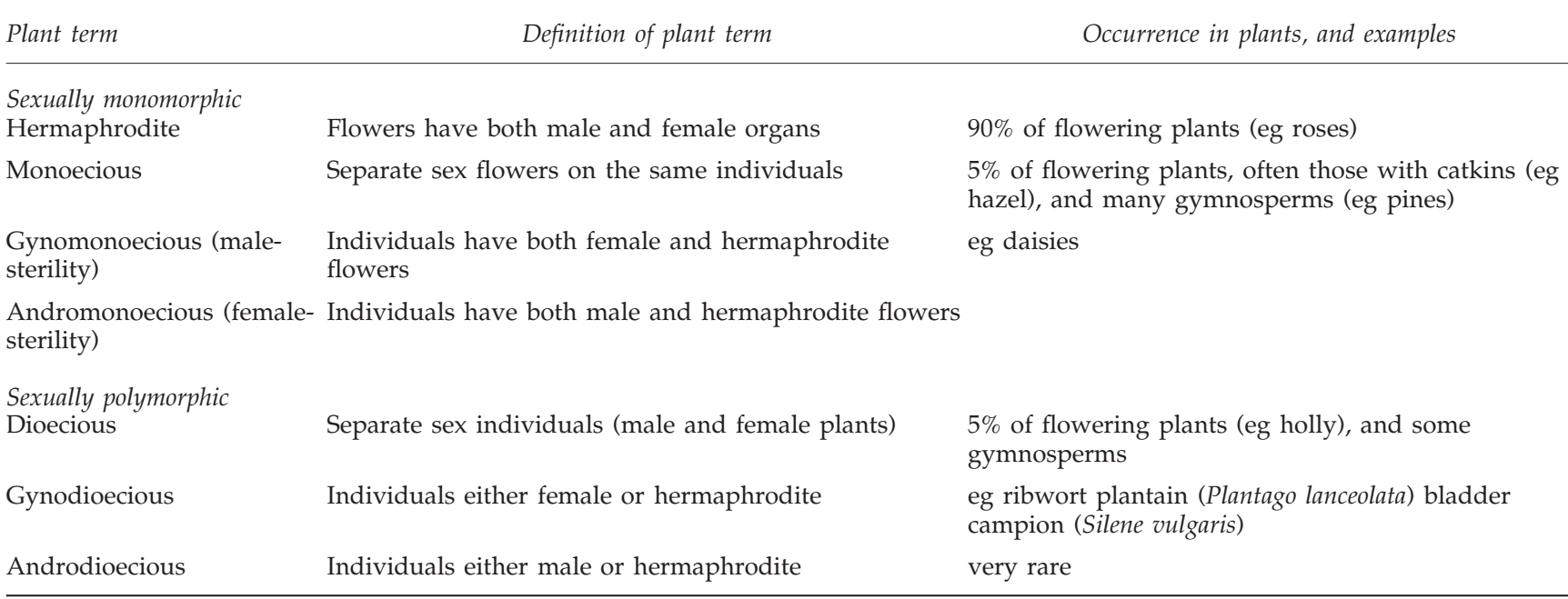

Several kinds of evidence suggest the involvement of two loci in sex determination. Some data come from crosses between dioecious plants and related monoecious or hermaphrodite species (Westergaard, 1958). In Silene dioica and latifolia, there is direct evidence from cytological studies of $\mathrm{Y}$ chromosome deletions. There are three functionally different $Y$ chromosome regions (see Figure 2), the $S u^{\mathrm{F}}$ region, and two regions containing factors controlling early and late anther development (Westergaard, 1958; Grant et al, 1994; Farbos et al, 1999; Lardon et al, 1999). In these species, $X$ and $Y$ pairing in male meiosis is confined to the tips (Westergaard, 1958; Parker, 1990; Lardon et al, 1999), and recombination is absent for most of the $\mathrm{Y}$ chromosome.

\section{Why are sex determining loci linked?}

The evidence for multiple sex determining genes suggests that non-recombination between the $\mathrm{X}$ and $\mathrm{Y}$ chromosomes evolved to prevent recombination between these loci, since recombination would produce maladaptive phenotypes, particularly neuter individuals (Figure 3b; Lewis, 1942). It is widely assumed that the linkage evolved after establishment of unlinked male and female sterility genes, ie that these loci have been brought into proximity by inversions and/or translocations (Lewis, 1942). A genetic model of the evolutionary transition from cosexuality to dioecy suggests, however, that linkage may often be necessary from the outset (Charlesworth and Charlesworth, 1978a). Starting from cosexuality, the evolution of two sexes must generally require at least two genetic changes, one (male-sterility) creating females and the other (female-sterility) producing males (Figure 3a, Charlesworth and Charlesworth, 1978a). The process may sometimes have been more gradual, with partial sterility mutations (Lloyd, 1975a; Charlesworth and Charlesworth, 1978b). Plants and animals with a single sex-determining determining locus are probably often derived from systems with maledetermining chromosomes (Bull, 1983; Traut and Willhoeft, 1990), as separate sexes cannot evolve in a single mutational step from an initial hermaphroditic or monoecious state (except under the extremely improbable assumption that a mutation arises in a cosex whose heterozygotes have one sex, and homozygotes the other sex, eg $A a$ male and aa female).

The existence of inconstant males (but not females) in many dioecious species (eg Galli et al, 1993; Testolin et al, 1995) supports this scenario of a major recessive mutation leading to females, followed by selection for modifiers making the cosexes more male, as in Figure 3. Once females have been established in a population, the availability of their ovules favours higher investment in pollen output, so there is a selective pressure on the cosexual morph to evolve a greater male bias (Charlesworth and Charlesworth, 1978a). Modifier genes that make cosexes more male-like should, however, also reduce female fertility (Figure 3b), unless they are sex-limited in their expression. This counter-selects against such factors, so partial female-sterility factors are generally most likely to spread in a gynodioecious population if they are linked to the male-sterility gene (Charlesworth and Charlesworth, 1978a; Nordborg, 1994). The spread of alleles beneficial in one sex but not in the other (antagonistic pleiotropy) similarly depends on linkage (Charlesworth and Charlesworth, 1980; Rice, 1997). There will also be selection for tighter linkage between the male-sterility locus and modifier loci (Charlesworth and Charlesworth, 1978a). Thus a cluster of linked loci in a particular chromosomal region, with suppressed recombination, and containing the sex determining loci and loci affecting male functions, will probably evolve.

Sex-linked markers should permit tests of whether the region involved in sex determination in dioecious species is also a single chromosomal location in cosexual relatives, or whether the sex determining genes were initially on different chromosomes, and only later came into proximity. All diploid Silene species have the same chromosome number $(n=12)$, suggesting that translocations of whole chromosomes have not contributed to the enlarged $X$ and $Y$, though movements of lesser genome regions are possible. 
Cucurbitales (Bryonia, Ecballium,

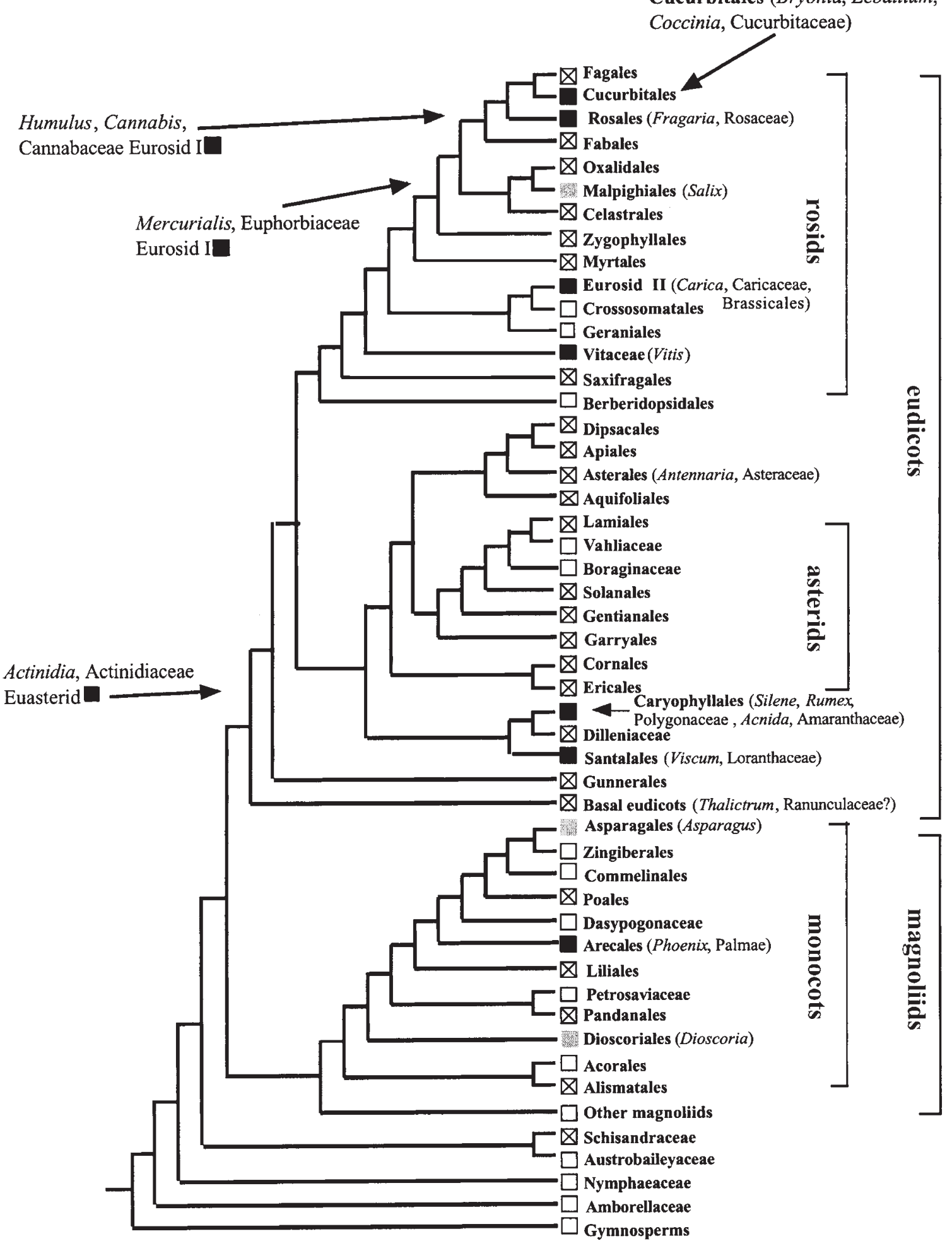

$\bigotimes$ Dioecy present

Sex chromosomes present

Sex chromosomes not present

Figure 1 The wide taxomic distribution of dioecy and sex chromosomes in angiosperms, based on the phylogenetic analysis of Soltis et al, (1999). Presence of dioecy is indicated by X inside a square. Filled symbols indicate taxa in which sex chromosomes have been studied. Black indicates the presence of species in which heteromorphic sex chromosomes have been found, either cytologically or by genetic mapping, and grey indicates that sex chromosomes are believed to be absent. 


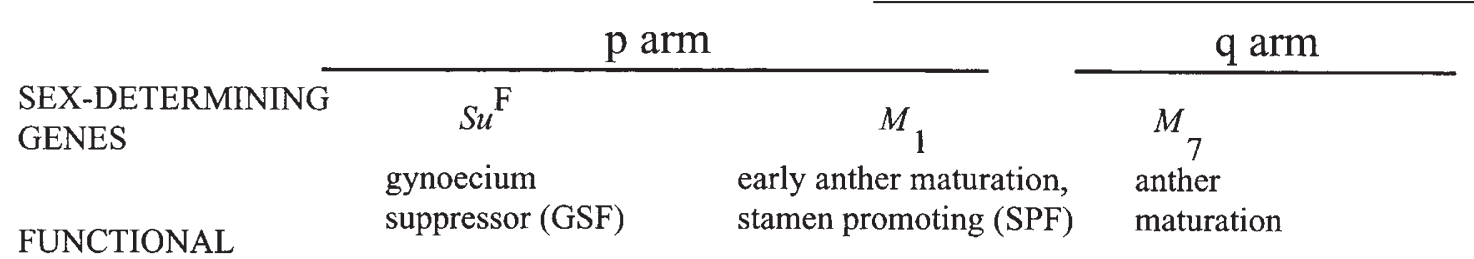

\section{REGIONS}

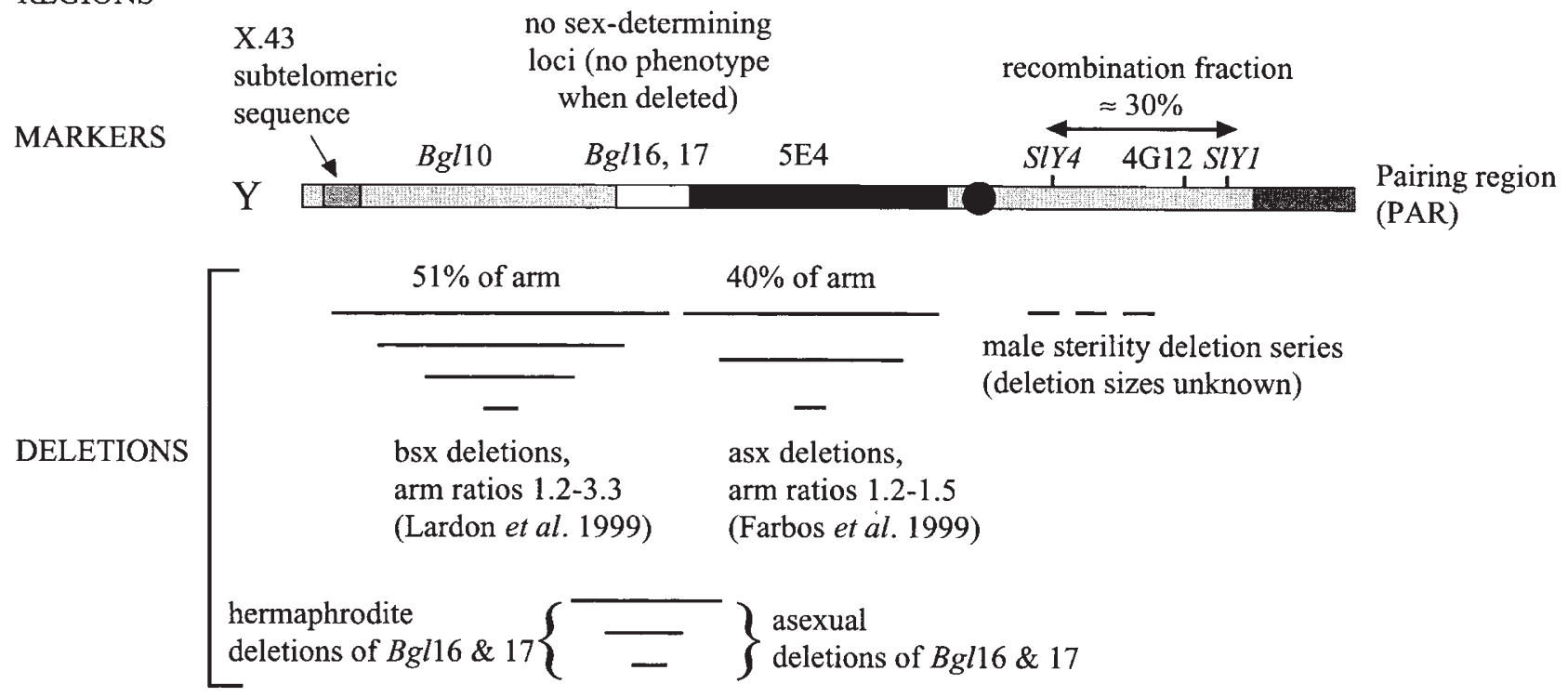

Figure 2 The Silene latifolia Y chromosome, showing genes and anonymous markers that have been identified. The deletions causing hermaphroditism ( $b s x$ mutations), and those causing complete sterility (ie early-stage anther abortion) of Y-bearing plants (as $x$ mutations), as well as the X-43 subtelomeric sequence, are described in Farbos et al (1999) and Lardon et al (1999), and the Bgl markers are described inDonnison et al (1996). The locations of the S1X4 and S1X1 loci are inferred from the finding of a male-sterile plant (with anthers aborted late in stamen development) which has no copy of S1X4 detectable by PCR, but which appears to carry a Y chromosome, since S1X1 is present (DA Filatov, unpublished data). The estimate of a recombination fraction of 30-40\% between S1X1 and S1X4 is based on unpublished data of V Laporte and V Hykelova.

\section{Evolution of sex chromosomes}

The theory outlined here explains the evolution of a rarely recombining chromosome region containing the sex determining genes, an incipient sex chromosome system. The female haplotype carries a recessive male-sterility allele, while the dominant male-determining chromosome would carry female-sterility alleles (and the wild-type allele at the male-sterility locus; Figure 3). Sex chromosome evolution is intimately connected with $\mathrm{Y}$ chromosome degeneration. Most current understanding of how the distinctive properties of $\mathrm{Y}$ chromosomes evolved comes from theoretical work on the evolution of genomic regions with low recombination. Such regions are subject to several processes, given a sufficiently high rate of deleterious mutations (Charlesworth and Charlesworth, 2000).

One process is mutation accumulation by Muller's ratchet (Muller, 1964; Haigh, 1978), leading to an increasing number of mutations, which become fixed as the process continues (Charlesworth and Charlesworth, 2000). Drosophila population sizes may be too high for this stochastic process to explain neo-Y chromosome degeneration (Charlesworth, 1996), and most plants have more chromosomes, and therefore fewer genes on a proto- $Y$ chromosome than on a Drosophila chromosome, so in plants the mutation rate to deleterious alleles may be too low. Another possibility is hitch-hiking: favourable mutant alleles arise on the proto- $Y$ and rise in frequency to fixation, concomitantly fixing deleterious alleles on the same chromosome (Rice, 1987). A third suggestion relies on accelerated fixation of deleterious mutations on a nonrecombining chromosome (because selection against deleterious alleles leads to reduced effective population size; Charlesworth, 1996). All these processes involve reduced effective population size, and should therefore lead to low Y-chromosomal genetic diversity (Charlesworth and Charlesworth, 2000).

The relatively recent origin of plant $\mathrm{Y}$ chromosomes, compared with those of most animals, make dioecious plants particularly suitable for studying the early stages of the degeneration process. The availability of closely related species, probably with chromosomes having gene content similar to that of the ancestral sex chromosomes, should show how genes have evolved since becoming sex-linked, offering a system to test between the different hypotheses. Most animal Y chromosomes degenerated long ago, making the processes responsible inaccessible to study, except in species with translocations between the sex chromosomes and autosomes. In species with $X-$ autosome translocations, the neo- $Y$ is not physically attached to the pre-existing $\mathrm{Y}$ chromosome, so its degeneration may result largely from the same kind of processes as in the initial evolution of $\mathrm{Y}$ chromosomes, but this is not certain. In plants, however, a there is de 
a

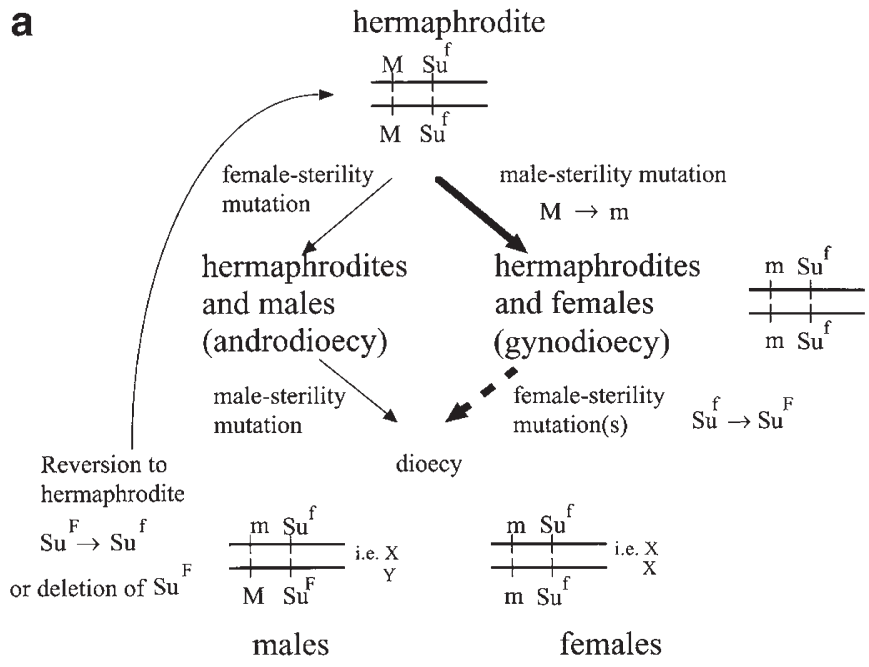

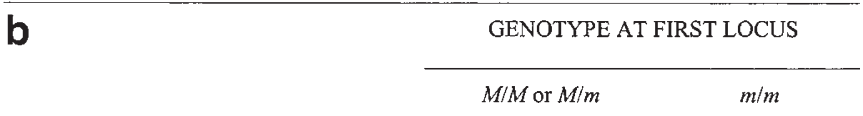

GENOTYPE AT MODIFIER LOCUS $S u^{\mathrm{f}} / S u^{\mathrm{f}}$

$S u^{\mathrm{f}} / S u^{\mathrm{F}}$ or $S u^{\mathrm{F}} / S u^{\mathrm{F}}$

Male

Neuter

EFFECTS OF CHANGE

On fertility

Hermaphrodite male

Female

fertility increased

fertility decreased

On fitness

Increased

Decreased

Figure 3 (a) The possible genetic changes that could occur in the transition from cosexual to separate sexed populations. (b) Effects of a female-sterility 'modifier' allele on hermaphrodites and females, in the absence of sex-limitation of its phenotypic effects. A trade-off between male and female functions is assumed, so that a gene increasing male fertility will often have the effect of reducing female fertility.

novo evolution of $\mathrm{Y}$ chromosomes. If plant, as well as animal Y chromosomes have degenerated, this would be evidence that the process is very general.

\section{Have plant $\mathrm{Y}$ chromosomes degenerated?}

Before using plants to study genetic degeneration, we need to know if their $\mathrm{Y}$ chromosomes are indeed degenerating. The evidence from the best studied species suggests some degeneration. Rumex acetosa $Y$ chromosomes are heterochromatic (Clark et al, 1993; Réjon et al, 1994; Lengerova and Vyskot, 2001). On the other hand, DNAse digestion experiments suggest transcriptional activity of this $\mathrm{Y}$ chromosome (Clark et al, 1993), though this could be due to the presence of dispersed repetitive sequences that are transcribed, such as transposable elements. The high frequency of chromosome rearrangements in this species (Wilby and Parker, 1988), and variability of its Y chromosome morphology (Wilby and Parker, 1986), are consistent with such a possibility, but it has not yet been tested. Some $X$-linked mutations are not masked by the Rumex Y chromosome (Smith, 1963), ie males are hemizygous for this region, like classical sex-linked loci in many animals.

In Silence latifolia, the two $\mathrm{X}$ chromosomes differ in the time of replication, as might be expected if one of them is transcriptionally silenced, and they appear to be differentially methylated, possibly indicating that dosage compensation is occurring by $X$ inactivation in females (Vyskot et al, 1999). Gene expression from Y chromosomes is suggested by estimates of methylation levels (Vyskot et al, 1993), which may imply that many Y-linked genes have not degenerated greatly, if at all (though again the possibility of transposons cannot be excluded). The large size of the $\mathrm{Y}$ chromosomes in S. latifolia and dioica (Costich et al, 1991) and many other dioecious plants (Parker, 1990), also suggests that plant Y chromosomes have accumulated repetitive sequences, which have been found on $\mathrm{Y}$ chromosomes of $S$. latifolia (Donnison et al, 1996; Zhang et al, 1998; Lardon et al, 1999) and $R$. acetosa (Réjon et al, 1994). So far, however, abundances are mostly similar on the $X$ and autosomes (Clark et al, 1993; Donnison et al, 1996; Scutt and Gilmartin, 1997). Thus the evidence is inconclusive, and the nature and range of kinds of such sequences is currently almost totally unknown.

In most studied species with heteromorphic sex chromosomes YY genotypes are inviable (see above), as are androgenic haploid plants of S. latifolia, with only a Y chromosome (Ye et al, 1990), while X-haploid plants are viable. However, the viability and fertility of occasional YY dihaploids (Vagera et al, 1994) argues against complete loss or inactivation of genes, presumably because increased gene dosage permits survival. Finally, female biased sex ratios in both S. latifolia (see Correns, 1928, but also Carroll, 1990) and Rumex acetosa (Smith, 1963; Wilby and Parker, 1988) as well as other dioecious species suggest that pollen grains with $\mathrm{Y}$ chromosomes grow more slowly than $\mathrm{X}$-bearing pollen. This suggests that plant $\mathrm{Y}$ chromosomes have reduced gene functions (Smith, 1963; Lloyd, 1974), though segregation distortion has not been ruled out (Taylor, 1994).

\section{Molecular genetics of plant $Y$ chromosomes}

Our understanding of the evolution of plant sex chromosomes and sex determination should be advanced by the use of molecular markers, so several groups are searching for these. The region containing the sex determining loci must initially have been fully homologous between the two alternative chromosomes. One goal of studies of plant sex chromosomes is therefore to test for homology. Both X-and Y-linked markers are now being discovered in plants with and without heteromorphic sex chromosomes (eg Testolin et al, 1995; Harvey et al, 1997; Polley et al, 1997; Zhang et al, 1998; Mandolino et al, 1999). Most markers are, however, anonymous, and cannot tell us which X-linked loci have homologues on the Y chromosomes and which do not.

Isolation of male-specific cDNAs from developing flower buds or reproductive organs has not yet led to discovery of sex determining genes (Matsunaga et al, 1996; Barbacar et al, 1997), probably because sex-determi- 
nation happens very early in flower development (Grant et al, 1994), so the genes identified are controlled in response to sex, rather than the controlling loci. Genes known to be important in floral development, including the homoeotic MADS-box genes also appear not to have direct roles in sex determination (Hardenack et al, 1994; Ainsworth et al, 1995). This is not surprising, as these mutations change floral organ identities, whereas in unisexual flowers apparently normal reproductive organs merely stop developing, as predicted by the genetic model above.

Both X- and Y-linked expressed loci have now been identified in S. latifolia. One approach is to directly search for sex-linked genes (Guttman and Charlesworth, 1998). This has identified the X-linked MROS-X (male reproductive organ specific) gene and its Y-linked homologue, MROS3-Y, which appears to have degenerated. MROS3$Y$ contains only a short region of homology to the MROS3-X sequence. This region has been evolving in a neutral manner, with a ratio of silent to replacement substitutions, $K_{\mathrm{a}} / K_{\mathrm{s}}$, of 0.974 , close to unity, as expected for a sequence evolving without selective constraints (Nei, 1987).

Another approach has isolated Y-linked genes present in mRNA populations from S. latifolia male flower buds. Two gene pairs have so far been characterised. Based on sequence similarity to other genes, the SIX/Y1 pair appears to encode a WD-repeats protein (Delichère et al, 1999) and SIX/Y4 a fructose-2, 6-bisphosphatase (Atanassov et al, 2001), and neither is likely to be involved in sex determination. The recombination fraction between SIX1 and SlX4 (Figure 2) suggests that they are far apart on the $X$, and potentially also on the $Y$ chromosome, unless this has been rearranged. Comparisons of the coding sequences of these X-and Y-linked genes, including outgroup sequences in non-dioecious Silene species, yield $K_{\mathrm{a}} / K_{\mathrm{s}}<0.2$ (Atanassov et al, 2001). The protein sequences of both the $\mathrm{Y}$ - and $\mathrm{X}$-linked genes have therefore been maintained for at least most of their evolutionary history since the $\mathrm{X}$ and $\mathrm{Y}$ ceased recombining, ie these Y-linked genes have not degenerated. Silent site divergence between SIX4 and SIY4 is similar to that between the X- and Y-chromosome copies of MROS3, and both suggest an age estimate of the sex chromosome system similar to that based on the ITS sequences (Desfeux et al, 1996). The SlX1 and SlY1 genes are considerably less diverged. It will be very interesting to study more $\mathrm{X} / \mathrm{Y}$-linked gene pairs to test whether the $\mathrm{Y}$ chromosome seems to have been built up in a stepwise manner, as seems to be true of the human Y (Lahn and Page, 1999; Waters et al, 2001).

If the $\mathrm{Y}$ chromosomes of dioecious Silenes are actively degenerating, Y-linked genes are predicted to have reduced diversity, and we can use patterns of diversity at non-degenerated loci (such as those just described) to test for selective sweeps. In samples from several $S$. latifolia and $S$. dioica populations, SIY1 diversity is indeed lower than that of SlX1, after correcting for the smaller number of $\mathrm{Y}$ than $\mathrm{X}$ chromosomes in populations (Caballero, 1995). Analysis using outgroup sequences shows that this is not due to a higher mutation rate of the Y-linked genes (Filatov et al, 2001). Tests such as Tajima's test do not suggest selective sweeps (Filatov et al, $2000,2001)$. However, these tests are affected by subdivision (Schierup et al, 2000), for which there is evidence in these species (McCauley, 1994; Giles et al, 1998; Ingvarsson and Giles, 1999; Richards et al, 1999), which probably affects the $\mathrm{Y}$ chromosome more than other chromosomes, because of its smaller effective size (Wang, 1999). Larger samples from within single populations are therefore needed. It is also difficult to test for diversity differences in the presence of introgression between the two Silene species. Y-chromosome variants differ between the two species, whereas some X-linked variants are shared between them (Filatov et al, 2001). A final difficulty is that autosomal loci are also needed in order to know whether Y-chromosomal variation is reduced, or X-linked diversity elevated. The one autosomal locus so far studied has low diversity, but this does not point to increased Xlinked diversity, because this gene appears to have experienced a selective sweep (Filatov et al, 2001), so more autosomal genes are needed. Comparisons are also needed with species whose Y-chromosome is fully degenerated. If low diversity is also found in these, it would point to causes such as mutation rate differences, rather than effects of the selective processes during genetic degeneration.

\section{Discussion}

With the availability of molecular techniques, we may now hope to understand more about how sex chromosomes evolve. Mapping data, even with anonymous markers, should give estimates of the fraction of X-linked loci that are located in the pairing and differential regions. In the absence of useful chromosome banding patterns that identify regions, single-copy anonymous markers can also be useful for mapping in combination with Y-chromosome deletions (Donnison et al, 1996). Deletion mapping of the $\mathrm{Y}$ chromosome does not precisely pinpoint the sex-determination loci, but it should be possible to define the regions in which these genes are located Figure 2 summarises current information about the $S$. latifolia $\mathrm{Y}$.

Once genes have been identified and sequenced, we will be able to estimate how long sex chromosome evolution takes. This should help us evaluate the plausibility of the proposed mechanisms for the process. The results of such studies may, in turn, contribute to our knowledge of mutation rates to deleterious mutations, and to a growing body of understanding of evolution in the absence of recombination. Studies of the early stages of sex chromosome degeneration offer the potential to have a eukaryote version of the interesting results on genome degradation in asexual prokaryotes (Wernergreen and Moran, 1999). If, as appears likely, plant sex chromosomes are found to be only partially genetically degenerated, they may offer opportunities to help understand the relationship between the evolution of genetic degeneration and of dosage compensation.

\section{Acknowledgements}

I think V Laporte and DA Filatov for many discussions during our work on sequences of S. latiofolia sex-linked genes. These genes were initially characterised in the lab of I Negrutiu and F Monéger, to whom thanks are due for providing sequence information without which our evolutionary studies could not have been done. DA Filatov was supported by a grant to D Charlesworth from 
the Leverhulme Trust, V Laporte by a grant from the BBSRC, and D Charlesworth by a NERC Senior Research fellowship.

\section{References}

Ainsworth CC, Crossley S, Buchanan-Wollaston V, Thangavelu M, Parker J (1995). Male and female flowers of the dioecious plant sorrel show different patterns of MADS box gene expression. Pl Cell 7: 1583-1598.

Atanassov I, Delichère C, Filatov DA, Charlesworth D, Negrutiu I, Monéger F (2001). A putative monofunctional fructose-2,6bisphosphatase gene has functional copies located on the $X$ and Y sex chromosomes in white campion (Silene latifolia). Mol Biol Evol 18: 2162-2168.

Barbacar N, Hinnisdaels S, Farbos I, Moneger F, Lardon A, Delichère C et al (1997). Isolation of early genes expressed in reproductive organs of the dioecious white campion (Silene latifolia) by subtraction cloning using an asexual mutant. Plant J 12: 805-817.

Bull JJ (1983). Evolution of Sex Determining Mechanisms. Benjamin/Cummings: Menlo Park, CA.

Caballero A (1995). On the effective size of populations with separate sexes, with particular reference to sex-linked genes. Genetics 139: 1007-1011.

Carroll SB, Mulcahy DL (1990). Progeny sex ratios in dioecious Silene latifolia. Am J Bot 80: 551-556.

Charlesworth D (1984). Androdioecy and the evolution of dioecy. Biol J Linn Soc 23: 333-348.

Charlesworth D (1985). Distribution of dioecy and self-incompatibility in angiosperms. In: Greenwood PJ, Slatkin M (eds), Evolution - Essays in Honour of John Maynard Smith. Cambridge University Press: Cambridge, pp 237-268.

Charlesworth B (1996). The evolution of chromosomal sex determination and dosage compensation. Curr Biol 6: 149-162.

Charlesworth B, Charlesworth D (1978a). A model for the evolution of dioecy and gynodioecy. Am Nat 112: 975-997.

Charlesworth D, Charlesworth B (1978b). Population genetics of partial male-sterility and the evolution of monoecy and dioecy. Heredity 41: 137-153.

Charlesworth D, Charlesworth B (1980). Sex differences in fitness and selection for centric fusions between sex-chromosomes and autosomes. Gent Res 35: 205-214.

Charlesworth B, Charlesworth D (2000). The degeneration of Y chromosomes. Phil Trans Roy Soc Lond B 355: 1563-1572.

Charlesworth D, Guttman DS (1999). The evolution of dioecy and plant sex chromosome systems. In: Ainsworth CC (ed), Sex Determination in Plants. BIOS, Oxford, pp 25-49.

Clark MS, Parker JS, Ainsworth CC (1993). Repeated DNA and heterochromatin structure in Rumex acetosa. Heredity 70 : 527-536.

Correns C (1928). Bestimmung, Vererbung and Verteilung des Geschlechtes bei den höheren Pflanzen. Handb. Vererbungswissenschaft 2: 1-138.

Costich DE, Meagher TR, Yurkow EJ (1991). A rapid means of sex identification in Silene latifolia by use of flow cytometry. Plant Mol Biol Reporter 9: 359-370.

Darwin CR (1877). The Different Forms of Flowers on Plants of the Same Species. John Murray: London.

Delichère C, Veuskens J, Hernould M, Barbacar N, Mouras A, Negrutiu I et al (1999). SIY1, the first active gene cloned from a plant $\mathrm{Y}$ chromosome, encodes a WD-repeat protein. $E M B O$ J 18: 4169-4179.

Desfeux C, Maurice S, Henry JP, Lejeune B, Gouyon PH (1996). Evolution of reproductive systems in the genus Silene. Proc $R$ Soc B 263: 409-414.

Donnison IS, Siroky J, Vyskot B, Saedler H, Grant SR (1996). Isolation of $\mathrm{Y}$ chromosome-specific sequences from Silene latifolia and mapping of male sex determining genes using representational difference analysis. Genetics 144: 1893-1901.

Farbos I, Veuskens J, Vyskot B, Oliveira M, Hinnisdaels S, Agh- mir A et al (1999). Sexual dimorphism in white campion: complex deletion on the $\mathrm{Y}$ chromosome results in a floral asexual type. Genetics 151: 1187-1196.

Filatov DA, Laporte V, Vitte C, Charlesworth D (2001). DNA diversity in sex linked and autosomal genes of the plant species Silene latifolia and S. dioica. Molec Biol Evol 18: 1442-1454.

Filatov DA, Monéger F, Negrutiu I, Charlesworth D (2000). Evolution of a plant Y-chromosome: variability in a Y-linked gene of Silene latifolia. Nature 404: 388-390.

Galli MG, Bracale M, Falavigna A, Raffaldi F, Savini C, Vigo A (1993). Different kinds of male flowers in the dioecious plant Asparagus officinalis L. Sex Plant Reprod 6: 16-21.

Giles BE, Lundqvist E, Goudet J (1998). Restricted gene flow and subpopulation differentiation in Silene dioica. Heredity 80: 715-723.

Grant S, Houben A, Vyskot B, Siroky J, Pan WH, Macas J et al (1994). Genetics of sex determination in flowering plants. Devel Genet 15: 214-230.

Guttman DS, Charlesworth D (1998). An X-linked gene has a degenerate Y-linked homologue in the dioecious plant Silene latifolia. Nature 393: 263-266.

Haigh J (1978). The accumulation of deleterious genes in a population. Theor Pop Biol 14: 251-267.

Hardenack S, Saedler H, Ye D, Grant S (1994). Comparison of MADS box gene expression in developing male and female flowers of the dioecious plants white campion. Plant Cell 6: 1775-1787.

Harvey CF, Gill, CP, Fraser LG, McNeilage MA (1997). Sex determination in Actinidia. 1. Sex-linked markers and progeny sex ratio in diploid A. chinensis. Sex Plant Repro 10: 149-154.

Heilbuth JC (2000). Lower species richness in dioecious clades. Am Nat 156: 221-241.

Ingvarsson PK, Giles BE (1999). Kin-structured colonization and small-scale genetic differentiation in Silene dioica. Evolution 53: 605-611.

Lahn BT, Page DC (1999). Four evolutionary strata on the human X chromosome. Science 286: 964-967.

Lardon A, Georgiev S, Aghmir A, Merrer GL, Negrutiu I (1999). Sexual dimorphism in white campion: complex control of carpel number is revealed by Y chromosome deletions. Genetics 151: $1173-1185$.

Lengerova M, Vyskot B (2001). Sex chromatin and nucleolar analyses in Rumex acetosa L. Protoplasma 217: 147-153.

Lewis D (1942). The evolution of sex in flowering plants. Biolog Rev 17: 46-67.

Lloyd DG (1974). Female-predominant sex ratios in angiosperms. Heredity 32: 35-44.

Lloyd DG (1975a). Breeding systems in Cotula. III. Dioecious populations. New Phytol 74: 109-123.

Lloyd DG (1975b). The transmission of genes via pollen and ovules in gynodioecy angiosperms. Theoret Pop Biol 9: 299-316.

Lloyd DG (1984). Gender allocations in outcrossing cosexual plants. In: Dirzo R, Sarukhan J (eds), Perspectives on Plant Population Ecology. Sinauer: Sunderland, Mass, pp 277-300.

Lloyd DG, Bawa KS (1984). Modification of the gender of seed plants in varying conditions. Evol Biol 17: 255-338.

Mandolino G, Carboni A, Forapani S, Faeti V, Ranalli P (1999). Identification of DNA markers linked to the male sex in dioecious hemp (Cannabis sativa L.). Theoret Appl Genet 98: 86-92.

Matsunaga S, Kawano S, Takano H, Uchida H, Sakai A, Kuroiwa $\mathrm{T}$ (1996). Isolation and developmental expression of male reproductive organ-specific genes in a dioecious campion, Melandrium album (Silene latifolia). Plant J 10: 679-689.

McCauley DE (1994). Contrasting the distribution of chloroplast DNA and allozyme polymorphism among local populations of Silene alba: implications for studies of gene flow in plants. Proc Natl Acad Sci USA 91: 8127-8131.

Muller HJ (1964). The relation of recombination to mutational advance. Mut Res 1: 2-9.

Nei M (1987). Molecular Evolutionary Genetics. Columbia University Press: New York. 
Nordborg M (1994). A model of genetic modification in gynodioecious plants. Proc Roy Soc Lond B 257: 149-154.

Okada S, Sone T, Fujisawa M, Nakayama S, Takenaka M, Ishizaki $\mathrm{K}$ et al (2001). The $\mathrm{Y}$ chromosome in the liverwort Marchantia polymorpha has accumulated unique repeat sequences harboring a male-specific gene. Proc Natl Acad Sci USA 98: 9454-9459.

Parker JS (1990). Sex-chromosome and sex differentiation in flowering plants. Chromosomes Today 10: 187-198.

Polley A, Seigner E, Ganal MW (1997). Identification of sex in hop (Humulus lupulus) using molecular markers. GENOME 40: 357-361.

Réjon CR, Jamilena M, Ramos MG, Parker JS, Rejon MR (1994). Cytogenetic and molecular analysis of the multiple sex-chromosome system of Rumex acetosa. Heredity 72: 209-215.

Renner SS, Ricklefs RE (1995). Dioecy and its correlates in the flowering plants. Am J Bot 82: 596-606.

Rice WR (1987). Genetic hitch-hiking and the evolution of reduced genetic activity of the $\mathrm{Y}$ sex chromosome. Genetics 116: 161-167.

Rice WR (1997). The accumulation of sexually antagonistic genes as a selective agent promoting the evolution of reduced recombination between primitive sex-chromosomes. Evolution 41: 911-914.

Richards CM, Church S, McCauley DE (1999). The influence of population size and isolation on gene flow by pollen in Silene alba. Evolution 53: 63-73.

Schierup MH, Vekemans X, Charlesworth D (2000). The effect of hitchhiking on genes linked to a balanced polymorphism in a subdivided population. Genet Res 76: 63-73.

Scutt CP, Gilmartin PM (1997). High-stringency subtraction for the identification of differentially regulated cDNA clones. Biotechniques 23: 468.

Smith BW (1963). The mechanism of sex determination in Rumex hastatulus. Genetics 48: 1265-1288.

Soltis PS, Soltis DE, Wolf PG, Nickrent DL, Chaw S-M, Chapman RL (1999). The phylogeny of land plants inferred from $18 S$ rRNA sequences: pushing the limits of rDNA signal? Mol Biol Evol 16: 1774-1784.

Taylor DR (1994). The genetic-basis of sex-ratio in Silene alba (=S. latifolia). Genetics 136: 641-651.
Testolin R, Cipriani G, Costa G (1995). Sex segregation ratio and gender expression in the genus Actinidia. Sex Plant Repr 8: 129-132.

Traut W, Willhoeft U (1990). A jumping sex determining factor in the fly Megaselia scalaris. Chromosoma (Berl.) 99: 407-412.

Vagera J, Paulikova D, Dolezel J (1994). The development of male and female regenerants by in-vitro androgenesis in dioecious plant Melandrium album. Ann Bot 73: 455-459.

Vyskot B, Araya A, Veuskens J, Negrutiu I, Mouras A (1993). DNA methylation of sex chromosomes in a dioecious plant, Melandrium album. Mol Gen Genet 239: 219-224.

Vyskot B, Siroky J, Hladilova R, Belyaev ND, Turner BM (1999). Euchromatic domains in plant chromosomes as revealed by $\mathrm{H} 4$ histone acetylation and early DNA replication. Genome 42: 343-350.

Wang J (1999). Effective size and F-statistics of subdivided populations for sex-linked loc. Theoret Pop Biol 55: 176-188.

Waters PD, Duffy B, Frost CJ, Delbridge ML, Graves JAM (2001). The human $Y$ chromosome derives largely from a single autosomal region added to the sex chromosomes 80-130 million years ago. Cytogenet Cell Genet 92: 74-79.

Weller SG, Wagner WL, Sakai AK (1995). A phylogenetic analysis of Schiedia and Alsinidendron (Caryophyllaceae: Alsinoideae): implications for the evolution of breeding systems. Syst Bot 20: 315-337.

Wernergreen JJ, Moran NA (1999). Evidence for genetic drift in endosymbionts (Buchnera): analyses of protein-coding genes. Mol Biol Evol 16: 83-97.

Westergaard M (1958). The mechanism of sex determination in dioecious plants. Adv Genet 9: 217-281.

Wilby AS, Parker JS (1986). Continuous variation in Y-chromosome structure of Rumex acetosa. Heredity 57: 247-254.

Wilby AS, Parker JS (1988). Mendelian and non-Mendelian inheritance of newly-arisen chromosome rearrangements. Heredity 60: 263-268.

Ye D, Installé P, Ciuperescu C, Veuskens J, Wu Y, Salesses G et al (1990). Sex determination in the dioecious Melandrium. I. First lessons from androgenic haploids. Sex Plant Repr 3: 179-186.

Zhang YH, DiStilio VS, Rehman F, Avery A, Mulcahy DL, Kesseli R (1998). Y chromosome specific markers and the evolution of dioecy in the genus Silene. Génome 41: 141-147. 